\title{
Indian Academy of Pediatrics - Integral Part of India Newborn Action Plan
}

\author{
VIJAY N Yewale \\ National President, Indian Academy of Pediatrics, 2014. \\ vnyewale@gmail.com
}

$\mathrm{T}$ he India Newborn Action Plan (INAP) was launched by the Government of India in September 2014 with an ambitious vision to end preventable neonatal deaths and stillbirths, and aiming at a single digit Neonatal mortality rate (NMR) and Still birth rate by 2030. Indian Academy of Pediatrics (IAP) was invited as a major partner to support and participate in this important initiative.

The trends of neonatal mortality in India in the past two decades show about $44 \%$ decline but there has been a disappointing stagnation in the early neonatal mortality rate (ENMR) at around 30 per thousand live births [1]. It is estimated that around $40 \%$ of all stillbirths and neonatal deaths take place during labour or within 48 hours. About three-fourths of the total neonatal deaths occur in the first week of life, with the first 24 hours accounting for more than one-third (37\%) of the deaths occurring during the entire neonatal period [2]. Since the ENMR is a yardstick for the maternal and child health care services, we need to urgently make efforts to improve this indicator of perinatal care. A complex diversity exists in the health care system in the country with NMR ranging from a low of 7/1000 live births in Kerala to a high of 30 or more per 1000 in Odisha, Madhya Pradesh, Uttar Pradesh, Rajasthan and Chhattisgarh. Also the NMR in rural areas is twice that in urban areas (33 vs 16 per 1000 live births) [2].

Recognizing the serious lacunae in health care equity, the INAP aspires to create a bridge ensuring equitable progress for girls and boys, rural and urban, rich and poor, and between districts and states. Importantly, it serves as a framework for states and districts to develop their own action plan with measurable indicators. The six pillars of interventions defined in this plan are : pre-conception and antenatal care; care during labour and child birth; immediate newborn care; care of healthy newborn; care of small and sick newborn; and care beyond newborn survival.
Another important highlight of the program is that for the first time focussed steps have been drafted by the Government of India for preventing stillbirths by constituting a Stillbirth Task Force to provide strategic oversight and technical guidance. Apart from strengthening of existing public health services at all levels, a web-based tracking system (Mother and Child Tracking System) to track every pregnant woman and child till the age of two years, and a web-based Health Management Information System (HMIS) data on a range of outputs and service delivery indicators at the facility level have been initiated.

In 2009, IAP had launched the Neonatal Resuscitation Program (NRP) - First Golden Minute (IAP-NRP-FGM) Project - in partnership with American Academy of Pediatrics (AAP) and Later-Day Saint Charities (LDSC) with academic grant from Johnson \& Johnson, India. Till date,over 70000 healthcare personnel have been trained in Basic and Advance NRP with aim to have presence of at least one NRP trained personnel at every delivery that takes place in India. In addition, IAP has formed alliances with various private organizations involved in enhancing the network of trained NRP professionals. The recognition of the efforts of the IAP by the Government of India has been a major boost to the Academy. The Academy has extended its complete support and commitment in this extremely important public health initiative, and will continue to strive to improve not just the perinatal and neonatal care but also the quality of life of these babies thereafter.

\section{REFERENCES}

1. UNICEF. India and Child Mortality in India. Levels, Trends and Determinants. Available from: http://www.unicef.org/ india/FactsheetExperts.pdf. Accessed October 26, 2014.

2. Ministry of Health \& Family Welfare. Government of India. INAP: India Newborn Action Plan. September 2014. Available from: http://www.newbornwhocc.org/ INAP_Final.pdf. Accessed October 26, 2014. 